lớn tại Bệnh viện Việt Đức. Luận văn tốt nghiệp thac sĩ Y học, Đại học Y Hà Nội.

6. Gallusser $\mathbf{N}$, Barimani B, Vauclair $F$ (2021). Humeral shaft fractures. EFORT Open Rev, 6 (1), 24-34.

7. Muller ME., Allower M., Schneider R. (1992).
Manual of interal Fixation. Techniques recommended by the AO/ ASIF Group.

8. Hee HT., Low By., See HF., (1998). Surgical results of open reduction and plating of humeral shaft fractures. Ann Acad Med Singapore, 27(6), 772-775.

\title{
THỰC TRANG SỬ DỤNG KHÁNG SINH TRONG ĐIỀU TRI NỘI TRÚ TẠI TRUNG TÂM Y TẾ HUYÊ̂N YÊN DŨNG, TİNH BẮC GIANG NĂM 2020
}

\section{TÓM TẮT}

Mục tiêu: Mô tả thực trạng sử dụng kháng sinh trong điều trị nội trú tại Trung tâm y tế (TTYT) huyện Yên Dũng, tỉnh Bắc Giang năm 2020. Phương pháp nghiên cứu: Nghiên cứu áp dung thiết kế nghiên cứu mô tả cắt ngang. Số liệu được hồi cứu từ dữ liệu trong phần mềm của khoa Dược và khảo sát 300 bênh án được rút ngẫu nhiên từ các bệnh án nội trú từ 01/01/2020-31/12/2020 tai TTYT huyê̂n Yển Dũng, tỉnh Bắc Giang. Các chỉ sổ chính của nghiên cứu bao gồm: Số lượng kháng sinh được sử dụng trong năm (tính theo DDD); phân loại KS theo cấu trúc hóa học; số ngày dùng kháng sinh; tỷ lệ bệnh án có phối hợp kháng sinh; kết quả điều trị sau khi dùng kháng sinh. Kết quả chính: Kháng sinh (KS) nội chiếm 54,54\% tính theo giá trị DDD (DDD - Defined Dose Daily - là liều trung bình duy trì hằng ngày với chỉ định chính của một thuốc KS); KS nhóm beta-lactam chiếm trên $80 \%$; 65,33\% số bệnh án được kê 1 loại KS; 30,33\% số bệnh án có kê 2 loại $\mathrm{KS}$; đáng lưu ý là một tỷ lệ nhỏ $(4,33 \%)$ số bệnh án phối hợp 3 loại KS trong điều trị; $54,33 \%$ số bệnh án có chỉ đinh KS từ 5-7 ngày; $43,33 \%$ bệnh án có kê KS từ 7-10 ngày; đặc biệt có 2,34\% bệnh nhân phải điều trị KS trên 10 ngày (chủ yếu ở khoa ngoai); 66,0\% bệnh nhân khỏi bệnh hoàn toàn và $31,3 \%$ bênh nhân tiến triển tốt sau khi đước chỉ định điêuu trị bằng KS và các thuốc phối hợp. Kết luân: Nhìn chung TTYT Yên Dũng đã tuân thủ tốt các khuyến cáo của Bộ Y tế trong sử dụng $K S$ về số lượng; chủng loai và thời gian sử dụng. Tuy nhiên, còn tồn tai một số vấn đề cần cải thiện, đó là: tỷ lệ KS nội được sử dung trong bênh viên thấp hơn so với khuyến cáo của Bộ Y tế $(54,54 \%$ so với khuyến cáo là $75 \%)$; có $4,33 \%$ bênh án phối hợp tới 3 loai KS trong điêu tri; có một tỷ lệ nhỏ bệnh án $(2,34 \%)$ dùng $\mathrm{KS}$ dài ngày (trên 10 ngày, chủ yếu ở khoa ngoai).

Tư khóa: Sử dụng kháng sinh; điều trị nội trú

\section{SUMMARY}

\section{THE REAL SITUATION OF ANTIBIOTIC USE} FOR INPATIENTS OF YEN DUNG MEDICAL

*Hoc viện Y dược học cổ truyền Việt Nam

Chịu trách nhiệm chính: Phạm Phương Liên

Email: phamphuonglien22339@gmail.com

Ngày nhận bài: 10.9.2021

Ngày phản biên khoa hoc: 28.10.2021

Ngày duyệt bài: 12.11.2021
Phạm Phương Liên*

\section{CENTER, BAC GIANG PROVINCE IN 2020}

Objective: To describe the real situation of antibiotic use for inpatients of Yen Dung Medical Center, Bac Giang province in 2020. Methods: This is a cross -sectional study. Data was collected from two sources: 1-medicine management software; 2reviewing 300 medical records that were randomly withdrawed from all medical records of inpatients in Yen Dung Medical Center during the time between $01 / 01 / 2020$ and 31/12/2020. Key indicators of the study: Quantity of antibiotics used in the year (calculated in DDD); classification of antibiotics according to chemical structure; number of days of antibiotic use; rate of medical records with antibiotic combination; outcomes of antibiotic treatment. Main findings: Domestic antibiotics account for $54,54 \%$ (based on DDD indicator); the antibiotic group that has been used the most is beta-lactam $(81,68 \%)$; $65,33 \%$ medical reports having one kind of antibiotics; $30.33 \%$ of the medical records were prescribed with 2 types of antibiotics; there is a small percentage $(4.33 \%)$ of the medical records combined 3 types of antibiotics; $54,33 \%$ of medical reports that were prescribed antibiotics during 5-7 days; the rate of medical reports that were prescribed antibiotics during $7-10$ days is $43,33 \%$; it is particularly noteworthy that $2.34 \%$ of patients had to be treated with antibiotics for more than 10 days (mostly in the surgical ward of the hospital). Conclusions: In general, Yen Dung Medical Center has well complied with the Ministry of Health's recommendations on the use of antibiotics including the indicators related to quantity; type and duration of antibiotic use. However, there are still some issues that need to be improved, including: the rate of domestic antibiotics that have been used in Yen Dung Medical Center is lower than Ministry of Health's recommended index (54.54\% compared to MOH's recommendation of $75 \%$ ); there is a small percentage $(4.33 \%)$ of the medical records combined 3 types of antibiotics; it is particularly noteworthy $2,34 \%$ of medical reports that were prescribed a longterm antibiotic therapy (over 10 days - mostly in the surgical ward of the hospital).

Keywords: Antibiotic using; Inpatient treatment

\section{I. ĐĂT VẤN ĐỀ}

Trong giai đoạn hiện nay, kháng KS đã trở thành vấn đề cấp bách trên toàn cầu, đặc biệt là tại các nước đang phát triển. Tổ chức Y tế thế 
giới đã xếp Việt Nam vào danh sách các nước có tỳ lệ kháng KS cao trên thế giới (8). Vì vậy, các nỗ lực nhằm tăng cường sử dụng KS an toàn, hợp lý là một trong các vấn đề ưu tiên hàng đâu của ngành y tế Việt Nam. Do đó, việc đánh giá thực trạng sử dụng KS hiện nay là hết sức cần thiết nhằm đưa ra các khuyến nghị góp phần nâng cao hiệu quả sử dụng thuốc.

Trung tầm y tế huyện Yên Dũng, tỉnh Bắc Giang là một trong những địa chỉ khám chữa bệnh uy tín trong khu vực. Trong danh mục thuốc của bệnh viện, nhóm thuốc KS luôn chiếm tỷ trọng lớn. TTYT Yên Dũng luôn quan tâm đến việc nâng cao hiệu quả sử dụng KS trong điều trị. Tuy nhiên, cho đến nay chưa có nghiên cứu nào mô tả chi tiết thực trạng sử dụng KS tại TTYT căn cứ theo các tiêu chí của BYT. Xuất phát từ nhu cầu thực tiễn, chúng tôi tiến hành nghiên cứu "Mô tả thực trạng sử dụng kháng sinh trong điều trị nội trú tại Trung tâm y tế huyện Yên Dũng năm 2020". Các kết quả nghiên cứu nhằm cung cấp các bằng chứng tin cậy cho công tác lập kế hoạch quản lý tốt việc sử dụng KS tại TTYT Yên Dũng.

\section{II. ĐỐI TƯợNG VÀ PHƯƠNG PHÁP NGHIÊN CỨU}

Thiết kế nghiên cứu: Nghiên cứu sử dụng thiết kế mô tả cắt ngang, thu thập số liệu định lượng

Địa điểm nghiên cứu: TTYT huyện Yên Dũng, Bắc Giang

Thời gian nghiên cứu: 9/2020 - 7/2021

Đối tượng nghiên cứu. Thông tin được thu thập từ số liệu thống kê số lượng thuốc sử dụng tại TTYT huyện Yên Dũng - Bắc Giang năm 2020 (lưu trữ trong phần mềm quản lý của khoa Dược) và hồ sơ bệnh án của bệnh nhân điêu trị nội trú tại 07 khoa lâm sàng trong khoảng thời gian từ 01/01/2020 đến 31/12/2020.

Cõ̃ mấu nghiên cứu. Nghiên cứu đã tiến hành lựa chọn ngẫu nhiên 300 bệnh án có sử dụng KS để đánh giá thực trạng sử dụng KS tại TTYYT Yên Dũng.

Biến số nghiên cứu chính. Tham khảo bộ tiêu chí đánh giá việc quản lý, sử dụng KS trong bệnh viện, ban hành kèm theo quyết định số 5631/QĐ -BYT (1), chúng tôi xác định các biến số chính của nghiên cứu như sau:

Nhóm biến số thu thập từ dữ liệu máy tính: Các loại KS sử dụng; số lượng KS đã sử dụng; chi phí cho KS; liểu xác định hàng ngày (DDD Defined Dose Daily - là liều trung bình duy trì hằng ngày với chỉ định chính của một thuốc KS).

Nhóm biến số thu thập từ hồ sớ bệnh án: Tỷ lệ bệnh án có chỉ định KS; số loại KS được sử dụng cho mỗi bệnh nhân; kết hợp KS; thời gian dùng $\mathrm{KS}$...

Kỹ thuật, công cụ thu thập số liệu: Hồi cứu thông tin từ dữ liệu trong phần mềm quản lý thuốc của khoa Dược

Sử dụng bảng kiểm để trích lục các thông tin từ hồ sơ bệnh án của bệnh nhân

Xử lý và phân tích số liệu. Số liệu thu thập từ hồ sơ bệnh án được nhập vào phần mềm Epidata 3.1 và xử lý bằng phần mềm SPSS 16.0.

Đạo đức nghiên cứu. Nghiên cứu đã được chấp thuận bởi ban lãnh đạo TTYT huyện Yển Dũng - Bắc Giang. Nghiên cứu không thu thập các thông tin cá nhân, không can thiệp trực tiểp vào đối tượng nghiên cứu. Các thồng tin thu thập được chỉ nhằm mục đích nghiên cứu, không phục vụ cho bất cứ mục đích nào khác.

\section{KẾT QUẢ NGHIÊN CỨU}

Nghiên cứu đã tiến hành phân tích thực trạng sử dụng thuốc KS cho bệnh nhân nội trú trong khoảng thời gian từ 01/01/2020 đến 31/12/2020 tại TTYT huyện Yên Dũng thông qua số liệu lưu trữ trong phần mềm quản lý thuốc của khoa Dược. Một số kết quả chính thu được như sau:

Bảng 1. Cơ cấu về số lượng và giá trị tiêu thụ kháng sinh theo nguồn gốc xuât xứ

\begin{tabular}{|c|c|c|c|c|c|}
\hline \multirow{2}{*}{ STT } & \multirow{2}{*}{ Nội dung } & \multicolumn{2}{|c|}{ Số lượng sử dụng (DDD) } & \multicolumn{2}{c|}{ Giá trị (VNĐ) } \\
\cline { 3 - 6 } & & Số lượng & Tỷ lệ \% & Số lượng & Tỷ lệ \% \\
\hline 1 & Thuốc kháng sinh sản xuất trong nước & 40.377 & 54,54 & 1.856 .427 .106 & 65,20 \\
\hline 2 & Thuốc kháng sinh nhập khẩu & 33.648 & 45,46 & 990.696 .241 & 34,80 \\
\hline & Tống & $\mathbf{7 4 . 0 2 5}$ & $\mathbf{1 0 0}$ & $\mathbf{2 . 8 4 7 . 1 2 3 . 3 4 7}$ & $\mathbf{1 0 0}$ \\
\hline
\end{tabular}

Nhận xét: Trên $50 \%$ các KS sử dụng tại TTYT Yên Dũng là thuốc được sản xuất trong nước với số lượng 40.377 DDD (chiếm $54,54 \%$ ); và giá trị tiêu thụ của nhóm KS này chiếm $65,20 \%$. Thuốc KS nhập khẩu từ nước ngoài chiếm $45,46 \%$ và giá trị tiêu thụ chiếm $34,80 \%$.

Bảng 2. Cơ cấu kháng sinh theo nhóm

\begin{tabular}{|c|c|c|c|c|c|}
\hline STT & $\begin{array}{c}\text { Nhóm thuốc kháng } \\
\text { sinh }\end{array}$ & $\begin{array}{c}\text { Số lượng sử } \\
\text { dụng (DDD) }\end{array}$ & Tỷ lệ \% & Giá trị VNĐ & Tỷ lệ \% \\
\hline 1 & Beta - Lactam & 60.467 & 81,68 & 2.236 .359 .174 & 78,55 \\
\hline 2 & Quinolon & 1.154 & 1,56 & 156.591 .784 & 5,50 \\
\hline
\end{tabular}


VIETNAM MEDICAL JOURNAL N¹ - DECEMBER - 2021

\begin{tabular}{|c|c|c|c|c|c|}
\hline 3 & 5- nitroimidazol & 10.763 & 14,54 & 383.910 .035 & 13,48 \\
\hline 4 & Aminosid & 688 & 0,93 & 35.304 .329 & 1,24 \\
\hline 5 & Macrolid & 474 & 0,64 & 26.762 .959 & 0,94 \\
\hline 6 & Khác & 479 & 0,65 & 8.195 .066 & 0,29 \\
\hline & Tống & $\mathbf{7 4 . 0 2 5}$ & $\mathbf{1 0 0}$ & $\mathbf{2 . 8 4 7 . 1 2 3 . 3 4 7}$ & $\mathbf{1 0 0}$ \\
\hline
\end{tabular}

Kết quả bảng trên cho thấy nhóm kháng sinh Beta - Lactam được sử dụng nhiều nhất với 60.467 DDD $(81,68 \%)$ và chiếm $78,55 \%$ tổng giá trị tiêu thụ thuốc. Nhóm Macrolid được sử dụng ít nhất với 474 DDD $(0,64 \%)$, giá trị tiêu thụ cho nhóm này cũng chiếm tỷ lệ thấp nhất là $0,29 \%$.

Bảng 3. Số lượng kháng sinh được kê trong bệh án

\begin{tabular}{|c|c|c|}
\hline $\begin{array}{c}\text { Số lượng kháng } \\
\text { sinh }\end{array}$ & Số lượng & $\begin{array}{c}\text { Tỷ lệ } \\
(\%)\end{array}$ \\
\hline 1 kháng sinh & 196 & 65,33 \\
\hline 2 kháng sinh & 91 & 30,33 \\
\hline 3 kháng sinh & 13 & 4,34 \\
\hline Tống & $\mathbf{3 0 0}$ & $\mathbf{1 0 0}$ \\
\hline
\end{tabular}

Kết quả tại bảng trên cho thấy tỉ lệ bệnh án được kê 1 kháng sinh chiếm khoảng $2 / 3$ (65,33\%), có 91 bệnh án được kê phối hợp 2 kháng sinh (30,33\%) và có một số ít trường hợp bệnh nhân được kê phối hợp 3 kháng sinh (chiếm 4,34\%).

Bảng 4. Thời gian sử dụng kháng sinh

\begin{tabular}{|c|c|c|}
\hline Số ngày điều trị & Số lượng & Tỷ lệ (\%) \\
\hline $5-7$ ngày & 163 & $54,33 \%$ \\
\hline $7-10$ ngày & 130 & $43,33 \%$ \\
\hline$>10$ ngày & 7 & $2,34 \%$ \\
\hline Tống & $\mathbf{3 0 0}$ & $\mathbf{1 0 0 \%}$ \\
\hline
\end{tabular}

Số liệu trong bảng 4 đã chỉ ra; khoảng $1 / 2$ số bệnh nhân được chỉ định KS từ 5-7 ngày (54,33\%); số bênh nhân được chỉ định KS từ 7 10 ngày chiếm $43,33 \%$. Có một tỷ lệ nhỏ (2,34\%) số bệnh nhân phải sử dụng KS trên 10 ngày.

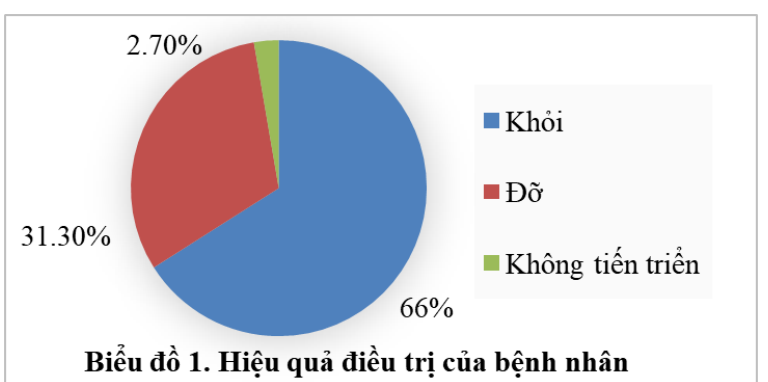

Căn cứ vào biểu đồ 1 , ta thây khoảng $2 / 3$ $(66,0 \%)$ số bệnh nhân sử dụng KS có hiệu quả điêu trị tốt; $31,3 \%$ cho kết quả đõ, thuyên giảm tình trạng bệnh sau khi dùng kháng sinh. Chỉ một tỷ lệ rất nhỏ $(2,7 \%)$ số bệnh nhân không tiến triển trong quá trình điều trị, phải chuyển tuyến.

\section{BÀN LUÂN}

Nghiên cứu của chúng tôi đã tiến hành khảo sát dữ liệu thống kê được lưu trữ trong phần mềm quản lý thuốc và 300 hồ sơ bệnh án nội trú được rút ngẫu nhiên tại TTYT huyện Yên Dũng. Nghiên cứu đã sử dụng nguồn số liệu và phương pháp thu thập số liệu khách quan, đáng tin cậy. Kết quả nghiên cứu cho thây nhìn chung TTYT huyện Yên Dũng đã tuân thủ tương đối tốt các qui định và khuyến cáo của BYT về sử dụng kháng sinh (4). Tuy nhiên, còn một số thiếu sót cần được lưu ý và có biện pháp điều chỉnh để cải thiện tốt hơn việc sử dụng KS tại TTYT. Cụ thế các kết quả thu được từ nghiên cứu như sau:

Tại TTYT Yên Dũng, tỷ lệ sử dụng thuốc KS nội đạt $54,54 \%$ và tỷ lẹ sử dụng thuốc KS nhập khẩu là 45,46\%. Tỷ lệ sử dụng kháng sinh nội tại TTYT Yên Dũng cao hơn tại bệnh viện Kiến An Hải Phòng vào năm 2019 (44,63\%) [7]. Hưởng ứng đề án "Người Việt Nam ưu tiên dùng thuốc Việt Nam", với mục tiêu nhằm tiết kiệm giá trị tiêu thụ thuốc trong khám, chữa bệnh góp phần đảm bảo an sinh xã hội, Bộ Y tế đã đưa ra chỉ tiêu: "tỷ lệ sử dụng thuốc nội trong danh mục thuốc tại các bệnh viện tuyển huyện đạt $75 \%$ vào năm 2020"[3]. Như vậy, nếu tính riêng nhóm KS, tỷ lệ thuốc nội được sử dụng tại TTYT Yên Dũng còn thấp hơn nhiều so với khuyến cáo của Bộ Y tế. Căn cứ vào thực trạng này, chúng tôi khuyến nghị TTYT Yên Dũng cần đưa ra kế hoạch, chính sách phù hợp nhằm tăng cường sử dụng KS sản xuất trong nước hơn nữa, hạn chế sử dụng các thuốc nhập khẩu có chứa hoạt chất thông thường. Thực hiện biện pháp này sẽ tiết kiệm được chi phí cho bệnh nhân đồng thời khuyến khích ngành công nghiệp dược trong nước phát triển.

Kết quả phân tích chi tiết về các nhóm KS cho thây, tî lệ sử dụng KS nhóm beta-lactam tại TTYT Yên Dũng rất cao, chiếm $81,68 \%$ số lượng (tính theo DDD) trong tổng số KS đã sử dụng. Chỉ số này tương đồng với kết quả khảo sát tại một số BV khác như BV C Thái Nguyên (78,5\%) [4], BV chấn thương, chỉnh hình tỉnh Nghệ An (77,9\%) [6]. Beta-lactam là một nhóm KS lớn, có số lượng các dược chất phong phú, phổ bao phủ được hầu hết các loại vi khuẩn gây bệnh hiện nay. Vì vậy, việc sử dụng nhiều nhóm kháng sinh 
này trong thực hành lâm sàng là hoàn toàn phù hợp về chuyền môn.

Kết quả phân tích số loại KS được kê trong một bệnh án tại TTYT Yên Dũng cho thấy: tỉ lệ bệnh án kê 1 loại KS là nhiều nhất $(65,33 \%)$. Tỷ lệ này tương đồng với kết quả nghiên cứu Nguyển Việt Hùng năm 2019 tại BVĐK tỉnh Điện Biên, tỉ lệ kê đơn 1 kháng sinh là 63,4\% [5]; Như vậy, có khoảng $1 / 3$ số bệnh án tại TTYT Yên Dũng có phối hợp từ 2 loại KS trở lên. Trong đó, đặc biệt có $4,34 \%$ bệnh án có phối hợp 3 loại KS. Theo cách khoa học nhất, chỉ định KS cần được căn cứ theo KS đồ và ưu tiên sứ dụng đơn trị liệu. Phối hợp KS chỉ được đặt ra với các trường hợp bệnh nhân không đáp ứng với đơn trị liệu. Do đó, TTYT huyện Yên Dũng cần xây dựng các tiêu chí cụ thể nhằm kiểm soát tốt hơn các trường hợp cần phối hợp KS.

Theo khuyênn cáo của Bộ $Y$ tế, thời gian sử dụng KS với nhiễm khuẩn nhẹ, đợt điều trị thường kéo dài từ 7 đến 10 ngày. Những trường hợp nhiếm khuẩn nặng, nhiễm khuẩn ở những tổ chức mà KS khó thâm nhập (VD: màng tim, màng não, xương - khớp...) đợt điều trị có thế kéo dài hơn [2]. Theo kết quả nghiên cứu tại TTYT huyện Yên Dũng, 54,33\% số bệnh án có chỉ định kháng sinh 5-7 ngày; 43,33\% bệnh án chỉ định KS 7-10 ngày. Đặc biệt lưu ý, có tỷ lệ nhỏ $(2,34 \%)$ bệnh án có số ngày sử dụng $K \dot{S}$ trên 10 ngày. Qua tìm hiểu, chúng tôi được biết chủ yếu các trường hợp dùng KS dài ngày ở khoa Ngoại do bệnh nhân sốt kéo dài sau phẫu thuật. Căn cứ vào kết quả trên, chúng tôi khuyến nghị, hội đồng thuốc và điều trị của TTYT cần theo dõi và xây dựng phác đồ dùng KS dự phòng trong phẫu thuật thủ thuật, tránh tình trạng phải dùng KS kéo dài sau phẫu thuật.

Số liệu khảo sát về kết quả điều trị cho thây: số bệnh nhân khỏi bệnh hoàn toàn sau khi ra viện chiếm tỷ lệ lớn (66\%); bệnh nhân đơ, giảm chiếm $31,33 \%$; bệnh nhân không thay đồi hoặc chuyển viện chiếm tỷ lệ thấp $2,67 \%$. Các chỉ số trên cho thấy việc chỉ định thuốc KS và các thuốc phối hợp tại TTY̛T Yên Dũng tương đối phù hợp, mang lại kết quả điều trị tốt cho bệnh nhân.

Tóm lại, trong nghiên cứu này bằng các phương pháp thu thập thông tin khoa học, chính xác và tin cậy, chúng tôi đã thu được các kết quả mô tả chi tiết tình hình sử dụng KS tại TTYT Yên Dũng dựa trên bộ tiêu chí đánh giá việc sử dụng KS của BYT. Tuy nhiên, trong nhiên cứu này, chúng tôi chưa đánh giá được chính xác mức độ phù hợp của các $\mathrm{KS}$ được chỉ định trong từng bệnh án cụ thể. Chúng tôi đề xuất các nhóm nghiên cứu sau nên phân tích sâu hơn để có thể đưa ra các khuyến nghị cụ thể nhằm nâng cao chất lượng điều trị bằng kháng sinh.

\section{KẾT LUẬN}

Nhìn chung TTYT Yên Dũng đã tuân thủ tốt các khuyến cáo của Bộ $Y$ tế trong sử dụng $K S$ về số lượng; chủng loại và thời gian sử dụng. KS nhóm beta-lactam chiếm trên $80 \% ; 65,33 \%$ số bệnh án được kê 1 loại kháng sinh; $54,33 \%$ số bệnh án có chỉ định KS từ 5-7 ngày, 43,33\% bểnh án có kê kháng sinh từ 7-10 ngày; $66,0 \%$ bệnh nhân khỏi bệnh hoàn toàn và $31,3 \%$ bệnh nhân tiến triển tốt sau khi được chỉ định điều trị bằng kháng sinh và các thuốc phối hợp. Tuy nhiên, còn một số điểm hạn chế cần được cải thiện bao gồm: tỷ lệ sử dụng KS nội thấp hơn so với khuyến cáo của Bộ Y Yể $(54,54 \%$ tính theo DDD, so với khuyến cáo là $75 \%$ ); có $4,33 \%$ bệnh án phối hợp tới 3 loại kháng sinh trong điều trị; có một tỷ lệ nhỏ bệnh án $(2,34 \%)$ dùng KS dài ngày (trên 10 ngày, chủ yếu ở khoa ngoại).

Căn cứ vào các kết quả trên, chúng tôi khuyến nghị TTYT Yên Dũng cần tăng cường sử dụng KS nội để giảm chi phí điều trị và xây dựng phác đồ dùng KS dự phòng trước phẫu thuật hợp lý để tránh tình trạng bệnh nhân phải dùng KS dài ngày sau phẫu thuật.

\section{TÀI LIỆU THAM KHẢO}

1. Bộ Y tế, Quyết định sỗ $5631 / Q \emptyset-B Y T$ ngày $31 / 12 / 2020$ về việc ban hành tài liệu "Hướng dẩn thực hiện quản lý sử dụng kháng sinh trong bệnh viện"

2. Bố Y ' tế, Hướng dẫn sử dung kháng sinh, 2015.

3. Bô̂ Y tế, Đề án "Người Việt Nam ưu tiên dùng thuốc Viết Nam", 2012.

4. Dung Hoàng Thị Kim, Phân tích thực trang sử dưng kháng sinh tại bệnh viện $C$ tỉnh Thái Nguyên nằm 2014, Luận văn thạc sỹ Dược học, Đại học Dược Hà Nội 2014.

5. Hùng Nguyển Vieêtt, Phân tích thực trạng tiêu thụ kháng sinh và việc sử dụng kháng sinhi trong điêu trị viêm phổi bệnh viện tại bệnh viện Đa khoa tỉnh Điện Biên, Luân văn thạc sỹ Dược học, Trường Đại học Dược Hà Nội, 2019 .

6. Khánh Hoàng Thí, Phân tích thực trạng sử dụng kháng sinh tại bệnh' viện chấn thướng - chỉnh hình Nghệ An năm 2016, Luận văn Dược sỹ chuyên khoa cấp II Trường Đại học Dược Hà Nội, 2018.

7. Thu Nguyển Thị Minh, Khảo sát thực trạng tiêu thu kháng sinh và cơ cấu kháng sinht điều trị nội trú tại bệnh viện Kiến An, thành phố Hải Phòng năm 2019่, Luận văn tốt nghiệp Dược sỹ đại học, Học viện Y Dược học cổ truyên Việt Nam, 20220.

8. World Health Organization, Cảnh báo tình trạng kháng kháng sinh ơ Viêt Nam,
http://www.medinet.hochiminhcity.gov.vn/quan-lyhttp://www.medinet.hochiminhcity.gov.vn/quan-ly-
duoc-my-pham/who-canh-bao-tinh-trang-khangkhang-sinh-o-viet-nam-cmobile4513-35717.aspx, 2020 , truy cập ngày $18 / 10 / 2021$. 